\title{
PENGARUH TEKANAN OPERASI TERHADAP LAJU ALIRAN HASIL FILTRASI ROTATING FILTER PADA ALIRAN TAYLOR- COUTTE POISEUILLE DI DALAM SILINDER KONSENTRIS
}

\author{
Sarip \\ Jurusan Teknik Mesin Sekolah Tinggi Teknologi Ronggolawe Cepu \\ Jl. Kampus Ronggolawe Blok B/I Mentul Cepu 58315 \\ E-mail: hidayatullohsarip566@gmail.com
}

\begin{abstract}
Abstrak: Tekanan operasi pada sistem Rotating Filter dapat mempengaruhi laju aliran penyaringan. Seksi uji penelitian menggunakan dua silinder konsentris yang silinder bagian dalam berputar berfungsi sebagai membran. Tujuan penelitian untuk mengetahui pengaruh tekanan operasi terhadap laju aliran penyaringan. Penelitian dilakukan dengan cara mengubah tekanan masuk ke dalam seksi uji dengan mengatur gate valve pada Rotating filter. Gate valve digunakan untuk mengontrol variasi tekanan operasi sesuai yang divariasikan. Variasi tekanan operasi yaitu: 77 $\mathrm{kPa}, 70 \mathrm{kPa}, 58 \mathrm{kPa}, 47 \mathrm{kPa}$, dan $39 \mathrm{kPa}$ dilakukan pada kondisi suhu campuran fluida $14^{\circ} \mathrm{C}$. Porousitas membran yang digunakan $1 \mu \mathrm{m}$ dengan debit umpan $Q_{\text {feed }}=0,2 \mathrm{gpm}$. Hasil penelitian menunjukkan bahwa pada tekanan $39 \mathrm{kPa}: 6,661 \mathrm{~L}^{2} \mathrm{~m}^{2} . \mathrm{mnt}, 47 \mathrm{kPa}: 6,777 \mathrm{~L}^{2} \mathrm{~m}^{2} . \mathrm{mnt}, 58 \mathrm{kPa} ; 6.864$ L/m ${ }^{2} . m n t, 70 \mathrm{kPa}: 6.950 \mathrm{~L} / \mathrm{m}^{2} . \mathrm{mnt}, 77 \mathrm{kPa}: 7.066 \mathrm{~L} / \mathrm{m}^{2} . \mathrm{mnt}$. Laju aliran meningkat saat tekanan operasi naik dan menurun saat waktu penyaringan bertambah. Laju aliran bertambah karena tekanan operasi naik menyebabkan daya dorong meningkat sehingga jumlah partikel yang terhambat semakin sedikit. Sedangkan laju aliran menurun karena jumlah partikel semakin meningkat sehingga terjadi fouling/pengendapan yang dapat menyebabkan efisiensi membran menurun.
\end{abstract}

Kata Kunci: Aliran Taylor-Coutte, Tekanan operasi, Laju aliran.

Abstract: The operating pressure in the Rotating Filter system can affect the filter flow rate. The study used a concentric two-cylinder test section and the inner cylinder to function as a membrane. The aim study to determine effect of membrane operating pressure on the filtering flow rate. To research conducted by changing pressure into test section by using gate valve on the rotating filter. Variations of operating pressure: $77 \mathrm{kPa}, 70 \mathrm{kPa}, 58 \mathrm{kPa}, 47$ $\mathrm{kPa}$, and $39 \mathrm{kPa}$ are carried out at $14^{\circ} \mathrm{C}$ fluid mixture temperature and porousity $1 \mu \mathrm{m}$ with $Q_{\text {feed }}=0.2 \mathrm{gpm}$. The results showed a pressure of 39 $\mathrm{kPa}:$ 6,661 L/ $\mathrm{m}^{2} . \mathrm{mnt}, 47 \mathrm{kPa}: 6,777 \mathrm{~L} / \mathrm{m}^{2} . \mathrm{mnt}, 58 \mathrm{kPa} ; 6,864 \mathrm{~L} / \mathrm{m}^{2} . \mathrm{mnt}$, $70 \mathrm{kPa}: 6,950 \mathrm{~L} / \mathrm{m}^{2} . \mathrm{mnt}, 77 \mathrm{kPa}: 7,066 \mathrm{~L} / \mathrm{m}^{2} . \mathrm{mnt}$. The flow rate increases as operating pressure rises and decreases as filtering time increases. The flow rate increases because the operating pressure rises causing the thrust to increase so that the number of inhibited particles is getting smaller. The flow rate decreases because the number particles increases so that fouling occurs which can cause membrane efficiency to decrease.

Keywords: Taylor-Coutte flow, operating pressure, flow rate. 


\section{PENDAHULUAN}

istem penyaringan dengan menggunakan membran dapat menimbulkan terjadinya fouling (pengendapan zat terlarut dan partikel yang tersaring) di permukaan atau dinding membran. Pengendapan dapat menyebabkan kinerja dan umur membran berkurang seiring lama waktu pemakaian. Salah satu solusi yang dilakukan untuk mengatasi masalah tersebut adalah dengan menggunakan sistem "Rotating Filter". Keuntungan membran berputar partikel yang menyumbat pori-pori membran sangat berkurang bila dibandingkan penyaringan biasa karena terjadi aliran Taylor-Couette pada celah antara membran dalam dan membran luar.

Penelitian yang dilakukan oleh Edward H.S, et al (2009), membran reverse osmosis yang digunakan untuk menyaring larutan $\mathrm{NaCl}$ yang diasumsikan sebagai air asin. Larutan $\mathrm{NaCl}$ dengan konsentrasi $2 \mathrm{mg} / \mathrm{L} ; 2,25 \mathrm{mg} / \mathrm{L} ; 2,5 \mathrm{mg} / \mathrm{L} ; 2,75 \mathrm{mg} / \mathrm{L}$ dan $3,0 \mathrm{mg} / \mathrm{L}$ disaring menggunakan membran spiral wound dengan merk Filtec USA TW 30-1812-100 dengan tekanan operasi dari 0,5 bar sampai 7 bar. Hasilnya menunjukkan bahwa kenaikan tekanan umpan menyebabkan kenaikan fluks hasil laju aliran penyaringan. Fluks maksimal diperoleh pada tekanan umpan 7 bar pada konsentarasi sampel 2,0 mg/L ditunjukkan pada Gambar 1.

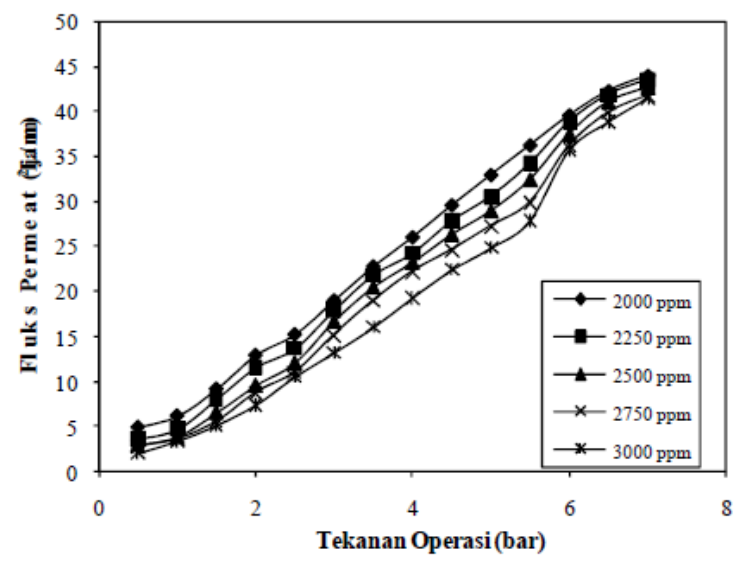

Gambar 1. Pengaruh tekanan operasi terhadap fluks pada beberapa konsentrasi larutan

(Edwar et al., 2009)

Lee dan Lueptow (2001) melakukan penelitian untuk mengetahui pengaruh kecepatan putar membran terhadap laju aliran (fluks) dengan tekanan lintas membran $(\triangle \mathrm{P}) 1800 \mathrm{kPa}$, dengan nilai REC sebesar 0,9 dan waktu operasi 1 jam. Penelitian menggunakan silinder dalam membran Reverse Osmosis dengan jari-jari $2,5 \mathrm{~cm}$ dan silinder luar dengan jari-jari 2,86 cm.

Untuk mengetahui pengaruh kecepatan putar membran terhadap laju aliran (fluks), Lee dan Lueptow (2011) melakukan penelitian dengan variasi nilai kecepatan, yaitu $0 \mathrm{rad} / \mathrm{min}, 70,8 \mathrm{rad} / \mathrm{min}, 86,5 \mathrm{rad} / \mathrm{min}, 157,3 \mathrm{rad} / \mathrm{min} \mathrm{dan} 314,6 \mathrm{rad} / \mathrm{min}$ dengan hasil kecepatan putar membran dapat memberikan efek yang besar terhadap laju aliran (fluks). Peristiwa Taylor Vortices yang ada di annulus, menyebabkan kinerja dari penyaringan membran meningkat. Hal ini membuat polarisasi konsentrasi yang terjadi di dekat membran menjadi berkurang, ditunjukkan pada Gambar 2. 


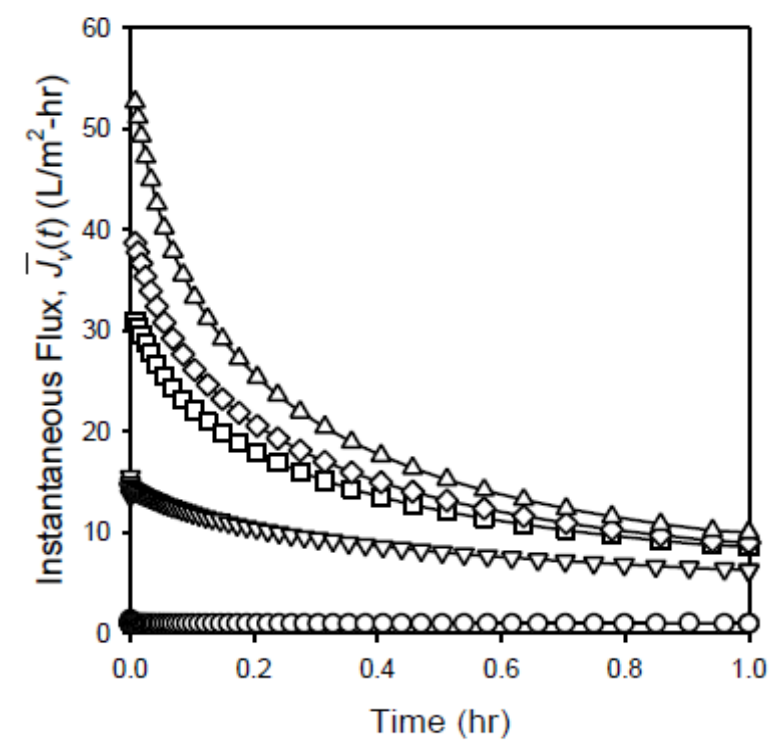

Gambar 2. Pengaruh berbagai kecepatan putar silinder dalam, terhadap laju aliran/fluks (Lee dan Leuptow, 2001)

Aliran fluida di antara dua buah silinder konsentris dimana silinder bagian dalam berputar dan silinder luar diam disebut dengan aliran Taylor-Couette atau aliran Couette melingkar. Sistem koordinat dalam aliran Couette melingkar dapat diperhatikan pada gambar 3. Persamaan momentum arah sumbu $\theta$ pada kondisi laminer, tunak untuk aliran di antara dua buah silinder konsentris berputar pada persamaan 1.

$\frac{\partial}{\partial r}\left(\frac{1}{r} \frac{\partial}{\partial r}\left(r u_{\theta}\right)\right)=0$

Sehingga diperoleh penyelesaian umum :

$u_{\theta}=c_{1} \mathrm{r}+\frac{\mathrm{c}_{2}}{\mathrm{r}}$

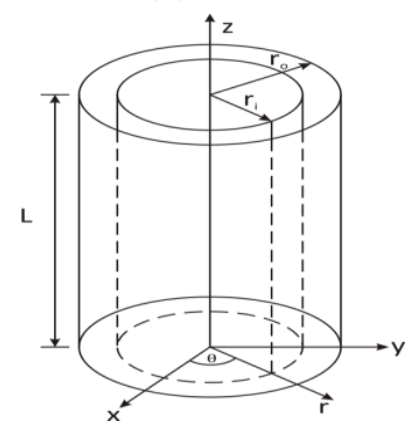

Gambar 3. Sistem geometri pada aliran Couette melingkar diantara dua buah silinder konsentris

Dengan kondisi batas:

$u_{\theta}=\Omega_{i} \mathrm{r}_{\mathrm{i}}$ pada $\mathrm{r}=\mathrm{r}_{\mathrm{i}}$

$u_{\theta}=\Omega_{0} \mathrm{r}_{0}$ pada $\mathrm{r}=\mathrm{r}_{0}$

$u_{\theta}=\frac{r_{i}^{2} \Omega_{i}-r_{0}^{2}}{r_{i}^{2}-r_{0}^{2}} r+\frac{r_{i}^{2} r_{0}^{2}\left(\Omega_{0}-\Omega_{i}\right)}{r_{i}^{2}-r_{0}^{2}} \frac{1}{r}$

Jika $\Omega_{0}=0$, maka

$u_{\theta}=\frac{r_{i}^{2} \Omega_{i}}{r_{i}^{2}-r_{o}^{2}} r-\frac{r_{i}^{2} r_{o}^{2} \Omega_{i}}{r_{i}^{2}-r_{o}^{2}} \frac{1}{r}$

Jika $\Omega_{0}=0$, maka 


$$
u_{\theta}=\frac{r_{i}^{2} \Omega_{i}}{r_{i}^{2}-r_{o}^{2}} r-\frac{r_{i}^{2} r_{o}^{2} \Omega_{i}}{r_{i}^{2}-r_{o}^{2}} \frac{1}{r}
$$

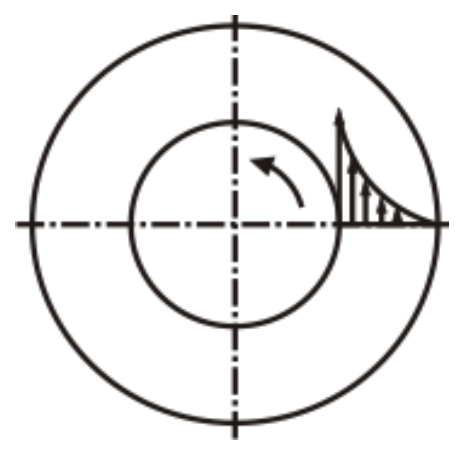

Gambar 4. Profil kecepatan aliran Couette melingkar diantara dua buah silinder konsentris

Ketidakstabilan yang terjadi pada aliran Couette di antara dua buah silinder konsentris yang berputar berhasil dipecahkan oleh G.I. Taylor pada tahun 1923. Taylor menemukan bahwa fenomena ketidakstabilan terjadi akibat dari gaya sentrifugal yang terjadi pada aliran Couette melingkar dapat mengatasi gaya viscous. Perbandingan antara efek gaya sentrifugal dan gaya viscous tersebut dinyatakan dengan bilangan nondimensi, Taylor number, Ta sebagai berikut:

$$
T a=\frac{\Omega_{1} R_{1} d}{v} \sqrt{\frac{d}{R_{1}}}
$$

Ketidakstabilan pertama terjadi jika putaran silinder dinaikkan hingga mencapai nilai $\mathrm{Ta}_{\text {kritis }}$ maka aliran laminar Couette melingkar akan berubah menjadi aliran Taylor vortex seperti terlihat pada Gambar 5. Aliran Taylor vortex ini dapat disebut sebagai aliran transisi sebelum terbentuk aliran turbulen penuh. Batas untuk ketiga daerah aliran tersebut diberikan dalam parameter bilangan Taylor sebagai berikut:

Ta $<41.3 \quad$ : aliran laminer Couette

$41.3<\mathrm{Ta}<400 \quad:$ aliran laminer dengan Taylor vortex

$\mathrm{Ta}>400 \quad$ : aliran turbulen

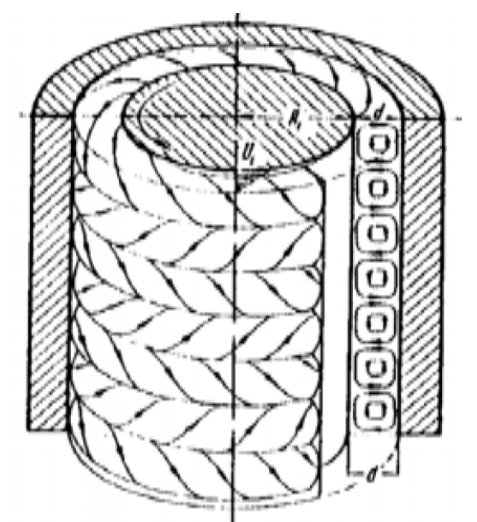

Gambar 5. Taylor vortex yang terjadi pada aliran Couette melingkar (Schlichting, 1979)

Di dalam proses filtrasi fluida padat dengan cair, cair dengan cair atau cair dengan gas memerlukan suatu media filter sebagai alat pemisahnya. Sedangkan filtrasi 
merupakan suatu proses dimana zat padat dipisahkan dari cairan atau gas dengan suatu media yang berpori mempertahankan padat tetapi memungkinkan fluida melewati atau suatu unit operasi yang dirancang untuk memisahkan partikel tersuspensi dari media cairan dengan melewatkan larutan melalui membran berpori atau yang lebih besar. Osmosis adalah bagian spontan cairan dari encer ke larutan lebih terkonsentrasi melintasi membran semipermeabel yang ideal yang memungkinkan bagian dari (air) pelarut tetapi bukan padatan terlarut (solut)/ Jika kekuatan exsternal dijalankan pada solusi yang lebih terkonsentrasi, kesetimbangan terganggu dan aliran pelarut terbalik.

Untuk Reverse Osmosis digunakan membran porous sintesis yang terbuat dari polimer. Bahan polimer yang dipakai adalah cellulose triacetate dengan metode produksi phase inversion, struktur membran-nya asimetrik sedangkan bentuknya berupa hollow fiber. Bahan cellulose banyak digunakan sebagai bahan pembuatan membran dialisis. Di samping properties yang sangat bagus untuk sebuah membran, akan tetapi jenis cellulose ester sangat sensitif terhadap degradasi panas, bahan kimia dan biologis. Untuk mencegah terjadinya hal tersebut, pHnya harus dijaga antara 4 dan 6,5 pada temperatur lingkungan.

\section{METODE PENELITIAN}

Bahan yang digunakan terdiri dari air sebagai fluida kerja dan serbuk plastik dengan ukuran $98 \mu \mathrm{m}-212 \mu \mathrm{m}$ sebagai zat campuran. Untuk melaksanakan penelitian dilakukan dengan skema alat penelitian sebagai berikut:

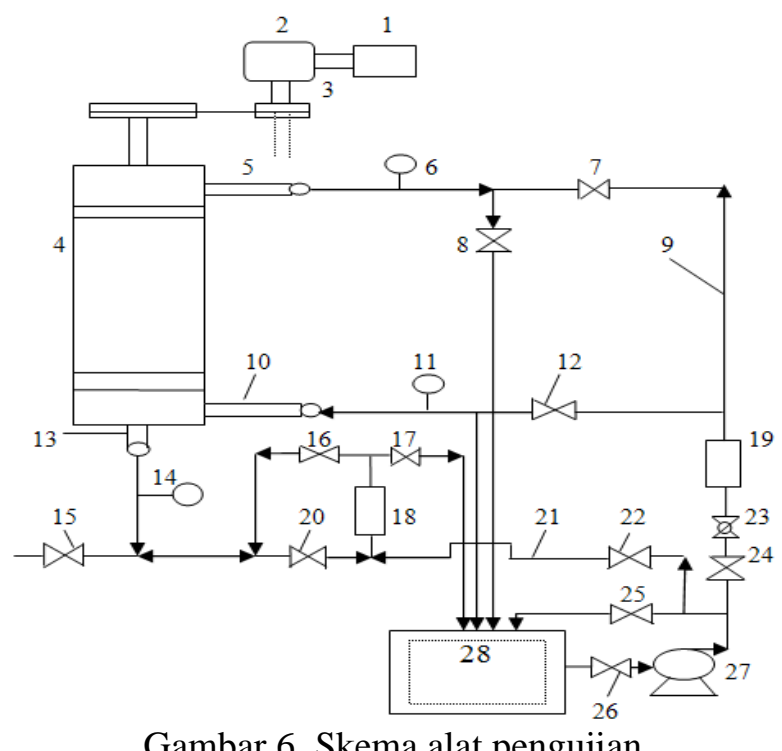

Gambar 6. Skema alat pengujian

Keterangan:

1. Inverter.

2. Motor listrik.

3. Pully transmisi.

4. Seksi uji.

5. Efluent.

6. Pressure transducer

7. Gate valve.

8. Gate valve.

9. Flushing
17. Gate valve.

18. Flow meter keluar.

19. Flow meter masuk.

20. Gate valve.

21. Flushing.

22. Gate valve.

23. Globe valve.
24. Gate valve.

25. Gate valve.

26. Gate valve.

27. Pompa.

28. Reservoar.
14. Pressure transducer

15. Gate valve.

16. Gate valve.
11. Pressure gauge.

12. Gate valve. 
Silinder bagian dalam diputar dengan motor listrik yang dihubungkan dengan sebuah inverter yang berfungsi untuk mengendalikan putaran. Variasi tekanan operasi membran diatur sesuai tekanan yang divariasikan dengan menggunakan gate valve. Secara singkat alur penelitian dapat dijelaskan sebagai berikut: membran diputar dengan tekanan operasi disesuaikan selama 45 menit. Laju aliran hasil penyaringan/fluks diukur mulai 1 menit sampai 45 menit dengan rentang waktu per 5 menit. Hasil pengujian tekanan operasi membran ditabelkan mulai dari $(77,70,58,47,39) \mathrm{kPa}$, kemudian dibuat grafik dan dianalisis dengan memberi penjelasan.

\section{HASIL DAN PEMBAHASAN}

\section{A. Hasil Penelitian Pengaruh Tekanan Operasi Membran}

Hasil penelitian pengaruh tekanan operasi membran disajikan pada Tabel 1.

Tabel 1. Hasil pengujian dengan variasi tekanan operasi membran.

\begin{tabular}{ccccccccccc}
\hline \multicolumn{10}{c}{ Fluks $\left(\mathrm{L} / \mathrm{m}^{2} . \mathrm{mnt}\right)$} \\
\hline Tek & \multicolumn{10}{c}{ Waktu (menit) } \\
\cline { 2 - 12 }$(\mathrm{kPa})$ & 1 & 5 & 10 & 15 & 20 & 25 & 30 & 35 & 40 & 45 \\
\hline 77 & 7.07 & 6.85 & 6.84 & 6.71 & 6.65 & 6.56 & 6.49 & 6.48 & 6.49 & 6.46 \\
\hline 70 & 6.95 & 6.84 & 6.71 & 6.66 & 6.59 & 6.52 & 6.46 & 6.38 & 6.37 & 6.35 \\
\hline 58 & 6.86 & 6.78 & 6.64 & 6.55 & 6.54 & 6.47 & 6.43 & 6.36 & 6.34 & 6.31 \\
\hline 47 & 6.78 & 6.68 & 6.56 & 6.52 & 6.46 & 6.41 & 6.37 & 6.35 & 6.28 & 6.27 \\
\hline 39 & 6.66 & 6.61 & 6.49 & 6.46 & 6.42 & 6.36 & 6.31 & 6.27 & 6.23 & 6.24 \\
\hline
\end{tabular}

\section{B. Analisa}

Hubungan antara fluks terhadap waktu penyaringan dengan variasi tekanan operasi membran dapat digambarkan seperti Gambar 5. Pada saat tekanan operasi sebesar $39 \mathrm{kPa}$, nilai fluks awal adalah $6,66 \mathrm{~L} / \mathrm{m}^{2}$.menit dan menurun hingga 6,24 $\mathrm{L} / \mathrm{m}^{2}$.menit pada menit ke-45. Pada saat tekanan operasi sebesar $47 \mathrm{kPa}$, nilai fluks awal adalah $6,78 \mathrm{~L} / \mathrm{m}^{2}$.menit dan menurun hingga $6,27 \mathrm{~L} / \mathrm{m}^{2}$.menit pada menit ke-45. Pada saat tekanan operasi sebesar $58 \mathrm{kPa}$, nilai fluks awal adalah $6,86 \mathrm{~L} / \mathrm{m}^{2}$.menit dan menurun hingga $6,31 \mathrm{~L} / \mathrm{m}^{2}$.menit pada menit ke-45. Pada saat tekanan operasi sebesar $70 \mathrm{kPa}$, nilai fluks awal adalah $6,95 \mathrm{~L} / \mathrm{m}^{2}$.menit dan menurun hingga $6,35 \mathrm{~L} / \mathrm{m}^{2}$.menit pada menit ke-45. Pada saat tekanan operasi sebesar $77 \mathrm{kPa}$, nilai fluks awal adalah 7,07 $\mathrm{L} / \mathrm{m}^{2}$.menit dan menurun hingga $6,46 \mathrm{~L} / \mathrm{m}^{2}$.menit pada menit ke- 45 .

Laju aliran penyaringan/fluks cenderung semakin menurun nilainya seiring bertambahnya waktu penyaringan terlihat pada Gambar 5. Menurunnya fluks sudah diprediksi sebelumnya karena adanya pengendapan partikel serbuk plastik pada permukaan membran yang menyebabkan aliran masuk melalui pori-pori membran terganggu.

Permasalahan yang timbul pada sistem filtrasi membran adalah pengendapan yang disebut fouling. Fouling yang terjadi pada dinding membran dapat menyebabkan kinerja membran menurun. 


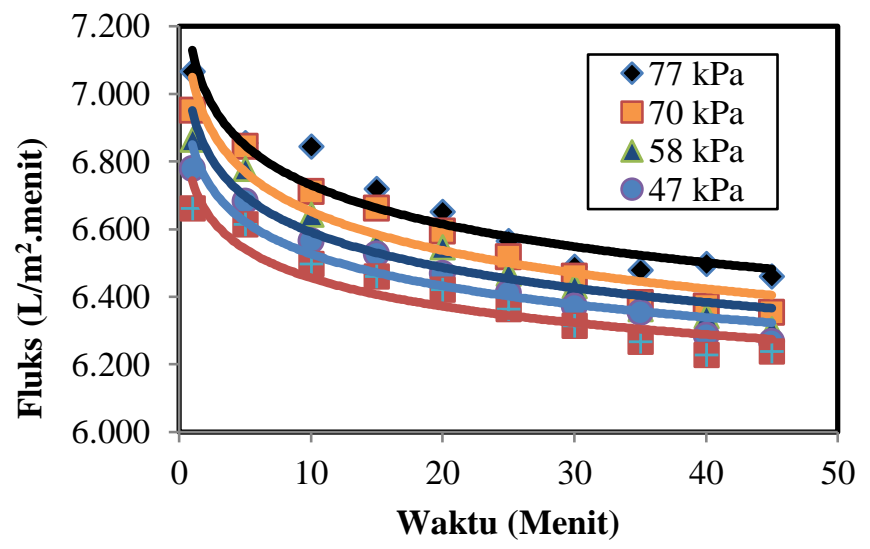

Gambar 7. Fluks penyaringan vs waktu dengan variasi tekanan operasi membran

Jika dilihat dari Tabel 1 dan Gambar 5, semakin meningkatnya tekanan operasi, maka fluks yang dihasilkan juga semakin tinggi karena gaya dorong yang dihasilkan oleh tekanan operasi membran meningkat sehingga jumlah aliran yang masuk ke dalam membran juga semakin besar. Tekanan operasi merupakan gaya dorong (driving force) untuk proses filtrasi dalam teknologi membran. Jadi semakin tinggi tekanan operasi, maka fluks yang dihasilkan juga semakin tinggi.

\section{KESIMPULAN}

Berdasarkan hasil penelitian mengenai variasi tekanan operasi membran terhadap laju aliran hasil filtrasi Rotating filter dapat disimpulkan sebagai berikut:

1. Nilai fluks meningkat seiring dengan bertambahnya nilai tekanan operasi membran. Hal ini terjadi karena gaya dorong naik sehingga menyebabkan jumlah aliran fluida yang melalui membran bertambah.

2. Nilai fluks menurun seiring bertambahnya waktu penyaringan karena adanya endapan partikel-partikel yang menempel pada dinding membran meningkat. Endapan-endapan partikel semakin lama semakin meningkat yang menyebabkan efisiensi membran menurun.

3. Nilai fluks meningkat akibat Rotating filter mempunyai gaya vortex yang terjadi di antara silinder konsentris. Gaya Vortex saling berpasangan untuk menyapu partikelpartikel yang menempel pada dinding membran. Aliran fluida di antara dua silinder konsentris juga menimbulkan gaya sentrifugal yang selalu menjauhkan partikelpartikel dari dinding membran.

\section{DAFTAR PUSTAKA}

Sutherland, Ken. (2008). Fiters and Filtration Handbook, Fifth Edition. BH.

Lathrop, D.P., Fineberg, J. \& Swinney, H.L. (1992). Transition to shear-driven turbulence in CouetteTaylor flow. Phys. Rev, 46(10), 6390-6405.

Lueptow, R.M., Docter, A \& Min, K. (1992). Stability of axial flow in an annulus with a rotating inner cylinder. Physics Fluid A, 4, 2446-2455.

Lueptow, R.M., \& Lee, S. (2004). Model Predictions and Experiments for Rotating Reverse Osmosis for Space Mission Water Reuse. Separation Science and Technology, 39(3), 539-561.

Lueptow, R.M., \& Min, K. (1994). Circular couette flow with pressure-driven axial flow and a porous inner cylinder. Experiment in Fluids, 17, 190-197. 
Lueptow, R.M., \& Pederson, C.L. (2006). Fouling in a high pressure, high recovery rotating reverse osmosis system. Desalination, 212, 1-14.

Rushton. A, A.S. Ward \& R.G. Holdich. (1996). Solid-Liquid Filtration and Separation Technology. New York, NY (USA): VCH Publishers, Inc.

Schlichting, H. (1979). Boundary Layer Theory. New York: McGraw-Hill.

Wereley, S.T., \& Lueptow, R.M. (1999). Velocity field for Taylor-Couette flow with an axial flow. Physics of Fluid, 11, 3637-3649.

White, F.M. (1991). Viscous Fluid Flow. New York: McGraw-Hill. 